\title{
FUZZY E O TECHIE: ENTRE AS CIÊNCIAS HUMANAS E AS TECNOLOGIAS DIGITAIS
}

\author{
J. F. RODRIGUES ${ }^{1}$ e M. H. B. C. DIÓGENES ${ }^{2}$
}

Instituto Federal de Educação, Ciência e Tecnologia do Rio Grande do Norte mhbc.helena@gmail.com²

Resenha submetida 14/08/2017 - Aceito 08/05/2020

DOI: $10.15628 /$ holos.2020.9626

\section{RESUMO}

Apresentamos a resenha da obra:

HARTLEY, S. (2017). O fuzzy e o techie: porque as ciências humanas vão dominar o mundo digital. Trad. Luis Dolhnikoff São Paulo: BEĨ Comunicação.

PALAVRAS-CHAVE: Fuzzy, Techie, humanistas, tecnicistas, profissional

\section{FUZZY AND TECHIE: BETWEEN HUMAN SCIENCES AND DIGITAL TECHNOLOGIES}

\section{ABSTRACT}

We present the review of the work:

HARTLEY, S. (2017). O fuzzy e o techie: porque as ciências humanas vão dominar o mundo digital. Trad. Luis Dolhnikoff São Paulo: BEĨ Comunicação.

KEYWORDS: Fuzzy, Techie, Humanists, Technicians, Professional 
Scott Hartley nasceu em 18 de julho de 1983, em Richland, Washington, EUA. É formado em Ciência Política. Dentre suas experiências de trabalho, consta a atuação no Center for Biomedical Ethics, de filosofia aplicada, no Google, no Facebook. É um capitalista de risco responsável por conhecer e avaliar as startups tecnológicas com objetivo de lançá-las e fazê-las crescer com sucesso.

O fuzzy e o techie Por que as ciências humanas vão dominar o mundo digital, primeiro livro de Scott Hartley, traz o debate sobre o valor das Ciências Humanas em um mundo dominado pela ciência e tecnologia reformulado sob um ponto de vista contrário à clássica oposição entre os profissionais dos dois campos - aos quais, o autor chama, retomando uma tradição universitária norte-americana, fuzzies ("humanistas") e techies ("tecnicistas"). À medida que avançamos em direção a um mundo cada vez mais tecnológico, o senso comum enxerga uma desvalorização da formação em Ciências Humanas.

Na obra, Scott Hartley nos revela exatamente o contrário: os fuzzies estão tomando um papel fundamental no desenvolvimento das ideias de sucesso mais criativas do mundo dos negócios, e sua colaboração com os techies é a chave para a dinâmica profissional do futuro. Hartley (2017, p. 10) argumenta que:

à medida que desenvolvemos nossa tecnologia para torná-la cada vez mais acessível e democrática, e à medida que se ela torna cada vez mais onipresente, as questões atemporais das ciências humanas e seus insights sobre as necessidades e os desejos humanos se tornam requisitos essenciais no desenvolvimento de nosso instrumental tecnológico.

Nesse sentido, este livro reúne diversos exemplos de colaboração entre os conhecimentos da área de humanidades e as habilidades técnicas e científicas no desenvolvimento de soluções criativas e inovadoras, como é o caso de alguns dos mais bem-sucedidos profissionais e de algumas das maiores companhias ao redor do mundo.

É um livro que busca a valorização das Ciências humanas e sociais e da ciência, tecnologia, Engenharia e Matemática. No que concerne à organização da obra, trata-se de uma narrativa composta por oito capítulos que se interrelacionam de forma a convergir na relação das ciências humanas e tecnológicas.

No Capítulo 1, intitulado: O papel do fuzzy em um mundo techie, o autor apresenta a origem dos termos que são usados na Universidade Stanford, sendo fuzzy para as pessoas que se formam em ciências humanas ou sociais, enquanto, os formados em engenharia ou ciência da computação são os techie. Preocupe-se, mas não tenha medo de pensar em si mesmo e interagir com o outro porque esta é uma característica exclusividade humana. Para tanto, a educação deve propiciar o desenvolvimento de habilidades mais completas e perspectivas mais amplas. Com as barreiras de acesso caindo, somos chamados às reflexões lançadas pelo autor: "qual o valor de uma formação em Ciências Humanas, especialmente se alguém quiser participar de forma significativa do alargamento dos limites de inovação tecnológica? As graduações em ciências humanas estão de fato excluídas das emocionantes possibilidades do futuro?" (HARTLEY, 2017, p. 24) 
Nessa perspectiva, em um mundo que muda cada vez mais rápido, a demanda é por agilidade, criatividade e curiosidade, para tanto as habilidades das Ciências Humanas são relevantes porque propiciam o desenvolvimento das habilidades fundamentais através do pensamento crítico, da compreensão de leitura, análise lógica, argumentação, comunicação clara e persuasiva. Mediante diversos relatos de profissionais, o autor destaca o valor que os mesmos expõem com paixão pelo fato de terem sido apresentados a Arte, a Antropologia, a Filosofia, a História, as religiões mundiais, a Literatura, as línguas, independente de sua formação ou carreira.

O autor nos chama atenção para o fato de que os fuzzies desempenham papéis centrais na apresentação de ideias mais criativas e bem-sucedidas, de modo que ajudam a reduzir o abismo entre as especialidades, numa ação coletiva por meio de equipes multidisciplinares na busca de como as novas tecnologias podem melhorar as nossas vidas.

As decisões são mais filosóficas do que técnicas, para isso é preciso tornar nossos valores claros e consistentes para serem interpretados e compilados pelas máquinas. Logo, a importância das Ciências Humanas está no fato de que a ela permite diversas formas de estudar, pesquisar, discutir, analisar, o mundo de modo mais amplo e dinâmico.

No capítulo 2, Adicionando o fator humano ao big data, Hartley afirma que adicionando insights humanos ao poder da tecnologia sem desconsiderar o valor humano nem a submissão integral das soluções tecnológicas, o homem deve aproveitar o poder do big data lidar com os problemas pendentes por análises cujas soluções exigem a interação da máquina, no sentido de agilizar e dar confiabilidade aos processos. $\mathbf{O}$ viés por trás dos dados aponta que dados não são objetos tampouco medidos apenas através dos números, sendo de diferentes tipos, origens e fins. O autor chama a atenção para o fato de que a Matemática pode ser utilizada para camuflar e perpetuar a discriminação. Adverte ainda que "não podemos eliminar os preconceitos da sociedade, mas podemos unir fuzzies e techeis para treinar nossos algoritmos, a fim de melhor peneirar e mitigar nossas fraquezas humanas" (HARTLEY, 2017, p. 59).

O poder da combinação dos fuzzies e techeis é mostrado pela maior empresa de coleta e análise de dados, Google, que mesmo dispondo das mentes analíticas mais brilhantes e das ferramentas tecnológicas mais poderosas, o seu poder está na liderança e competências pessoais.

O capítulo 3, intitulado: A democratização das ferramentas tecnológicas, a discussão é sobre as ferramentas disponíveis e como elas podem ser usadas de maneira inédita para criar inovações, sem necessidades de treinamentos profundos em tecnologia. O capítulo foca na programação de computadores que caminha para uma maior universalidade, no entanto o que importa mais do que saber programar é fazer saber quais perguntas você está fazendo e tentando resolver.

No capítulo 4, Algoritmos que nos ajudam - em vez de nos controlar, o autor nos remete a seguinte pergunta: quem serão os beneficiados com os sistemas que são desenvolvidos? Como direcionamento a reflexão Hartley (2017, p. 105) afirma que: a maior ameaça não é a tecnologia; é nossa priorização da tecnologia à custa de outros assuntos, como as ciências humanas, e a forma como formulamos as grandes questões para que nossas ferramentas sejam bem usadas. Devemos desenvolver a tecnologia não pela sua glamorização, mas conciliando-a e enriquecendo-a com a diversidade de 
pensamento. Nesse sentido, podemos aferir que o uso das tecnologias pode e deve estar a serviço da humanidade, para a uma sociedade justa e igualitária, que se preocupa e cuida de todos os seres do mundo, ou seja, a utilização da tecnologia em prol do benefício coletivo.

No capítulo 5, intitulado: Uma tecnologia mais ética, o autor expõe como uma geração de inovadores estão considerando as ideias de Donald Norman e Steve Jobs na aplicação das habilidades, ideias e sensibilidades cultivadas pelas ciências humanas para inovação tecnológica, na busca de criar produtos tecnológicos que proporcionem o bem estar humano. São destaques a promoção da ética do design, a proteção da nossa liberdade de escolha, a diferença na medicina preventiva e a terapia digital.

No capítulo 6, denominado: Melhorando a forma como aprendemos, são apresentadas experiências interessantes de uso das ferramentas tecnológicas na área da educação. São exemplos inovadores que buscam o equilíbrio no ensino, na melhoria do aprendizado combinado e conduzido por estudantes, com o envolvimento dos pais e no melhor que os fuzzies e techies podem contribuir para melhoria da educação.

Para ilustrar, apresentamos Sugata Mitra professor de tecnologia educacional da Universidade de Newcastle, que em 1999, abriu um buraco na parede do seu escritório em Nova Deli próximo a uma favela e colocou um computador dentro. As crianças correram até o dispositivo e dentro de poucas horas navegaram sem ajuda de adultos. Acessaram vídeos o aprenderam inglês suficiente para enviar e-mails e a função pesquisa. Ensine as crianças a serem criativas e boas comunicadoras, pois para Mitra, o que interessa na área digital é a capacidade de fazer perguntas, pensar criticamente e utilizar ferramentas para resolver problemas.

No capítulo 7, Para construir um mundo melhor, Hartley destaca a necessidade de se trabalhar juntos para tornar o mundo seguro, como também resolverem os problemas mais complicados, considerando que,

Uma grande ironia do desenvolvimento das tecnologias de alto poder de hoje é que muitas pessoas no planeta ainda estão passando pelos problemas mais básicos que afligiram a humanidade ao longo dos tempos: além das tragédias do conflito político e militar, elas sofrem de fome e doença, falta de educação e estagnação do desenvolvimento econômico (HARTLEY, 2017, p. 172)

Para tanto, faz-se necessário que os governos sejam agentes de mudanças e solucionadores de problemas com agilidade para atender as necessidades e direitos dos cidadãos.

No capítulo 8, o autor Hartley destaca o futuro do emprego diante dos avanços tecnológicos, gerou a globalização que levou a terceirização das massas de trabalhadores. Nesse sentido, o foco é na demanda por competências interpessoais que são o diferencial que propicia um aprendizado profundo, visto que as máquinas não podem intuir, criar ou sentir.

Ao lermos a obra, estamos diante de uma leitura instigante, em virtude de seu relevante conteúdo analítico e teórico. Consideramos que é uma obra de referência para todos que tem 
interesse pelas ciências humanas e um forte convite para os tecnológicos, pois o desafio é a união do fuzzy e do techie para a construção de um mundo melhor.

Por fim, salientamos as palavras de Hartley (2017, p. 187), que de forma reflexiva assinala que "[...] cultivar a nossa humanidade, em particular as competências interpessoais que as ciências humanas promovem, será a melhor maneira de garantir segurança para o trabalho". De forma que é fato que a gama de ferramentas tecnológicas pode promover o bem-estar da população, sendo necessário haver uma maior reflexão sobre as perspectivas advindas dos fuzzies com os techies.

\section{REFERÊNCIAS}

HARTLEY, S. (2017). O fuzzy e o techie: porque as ciências humanas vão dominar o mundo digital. Trad. Luis Dolhnikoff. São Paulo: BEĨ Comunicação. 